\title{
Rapid re-design of a postgraduate taught module for asynchronous delivery on the FutureLearn platform
}

\author{
Ikedinachi Ogamba \\ Coventry University, UK
}

Keywords: asynchronous learning design; content acquisition; active learning; FutureLearn; Covid-19.

\section{The challenge}

The module under discussion is a component for a Health Management Master's degree at a UK university, which attracts international students from various health- and management- related backgrounds. Pre-pandemic, it was taught through a series of faceto-face lectures and seminars, and delivered three times yearly with an average class size of 90 students per cohort. Although the university moved teaching and learning online at the onset of the Covid-19 lockdown, these were mainly synchronous classes taught through BigBlueButton on Moodle, Zoom, and MS Teams. Therefore, little consideration was given to other changes to students' and tutors' personal, familial, social, economic, and environmental circumstances, which complicated the transition to online learning and homeworking. Some of these circumstances include electricity and internet connectivity issues, sharing computer devices and disruption from household members, lack of convenient learning space, other demands on time schedules, and multitasking on other chores while learning online (Adedoyin and Soykan, 2020). The situation created barriers to fully engaging in synchronous classes, which saw a drop in students' participation. The recruitment of new intakes for May 2020, September 2020, and January 2021 included mostly international students who started studying from their various home countries due to the travel restrictions. Hence, learners' geographical differences and time zones was another major challenge for scheduling sessions to suit all. 
Therefore, beyond the traditional online synchronous lecture sessions, there was the need to enhance both the pedagogy and the virtual learning environments to adapt to the challenges of online learning during the Covid-19 pandemic.

\section{The response}

Between April and May 2020 there was a rapid redesign of the module, to support asynchronous delivery, through a collaborative approach involving a team of module tutors, online learning designers, and media technologists. The FutureLearn platform was chosen to offer students the benefits of flexible learning, access to teaching materials anywhere anytime, as well as the pedagogical benefits of active learning with tutors and peers (Owston, York and Murtha, 2013; Waha and Davis, 2014). FutureLearn is a popular VLE for Massive Open Online Courses (MOOCs) which has been used by some universities in the teaching and awarding of online degree programmes and microcredentials.

The design process started with a breakdown of the module structure through the application of constructive alignment (Biggs and Tang, 2011) to mapping out the module learning outcomes, indicative content, and the semester's ten weeks of lecture and seminar topics, and formative and summative assessments. Related weekly topics were paired to create two-week-long short courses with their relevant module level outcomes, content, and learning activities mapped, resulting in a total of five FutureLearn short courses. These were further developed using a detailed storyboarding process to map out each short course (Young and Perović, 2016).

The Conversational Framework (Laurillard, 2012) was utilised in the design process and uniquely applied using a two-prong approach: 'content acquisition development' and 'active learning tasks development'. Corresponding to constructionism pedagogy (Laurillard, 2020), this two-pronged approach was introduced to provide an online learning environment in which to develop and integrate concepts and practices from the tutors, learners, and their peers, to replace the usual face-to-face delivery of lectures and seminars/workshops. 


\section{Content acquisition development}

Acquisition is one of the major learning activities within the Conversational Framework, which requires the learner to read, watch, and/or listen, in order to develop concepts (Laurillard, 2012). Text, images/diagrams, audio/podcast, and videos were used in a combination of lecture and seminar styles, grounded in evidence from theory and practice to design concept delivery (Figure 1).

Figure 1. Content acquisition development overlap.

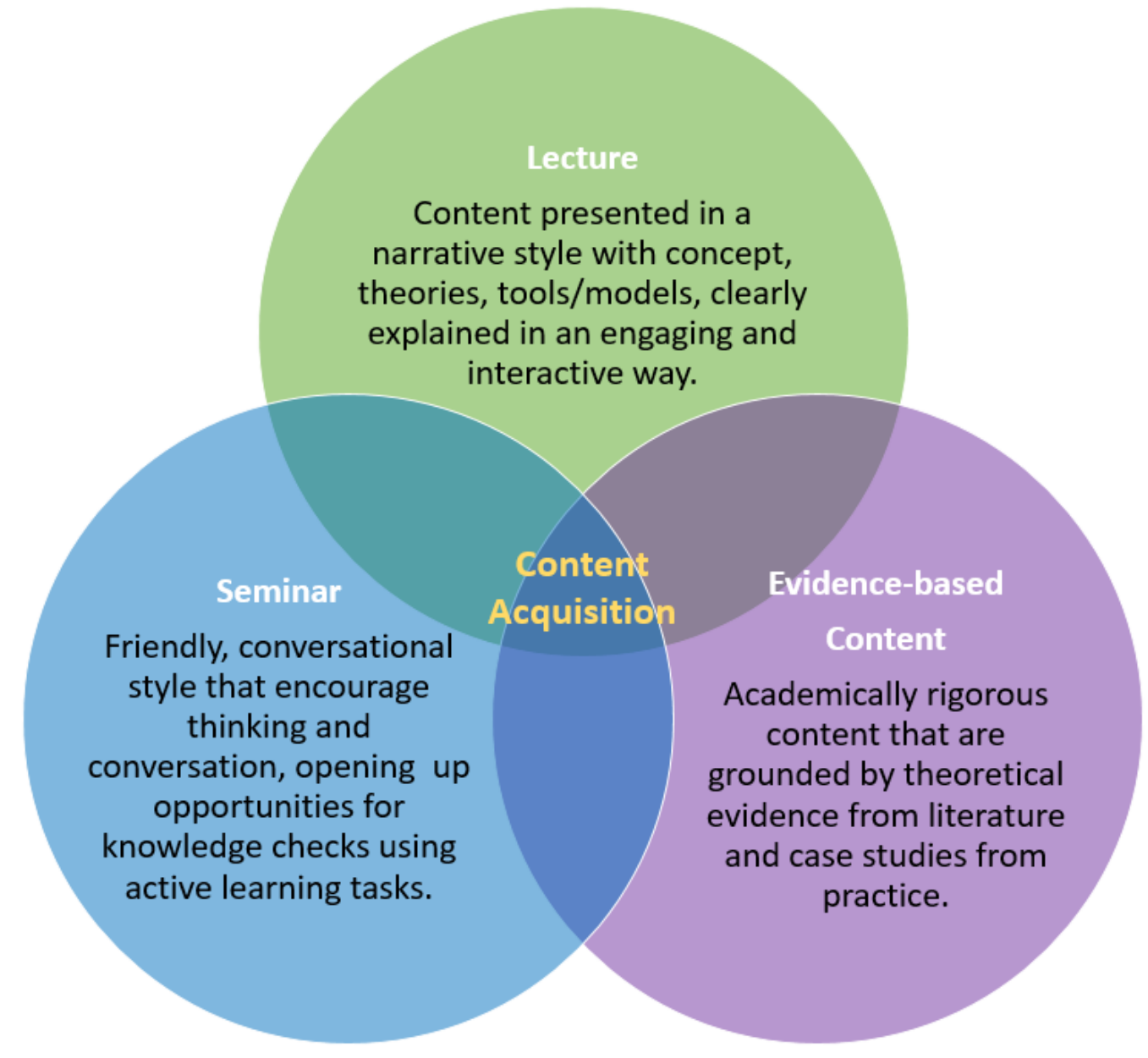

\section{Active learning task development}

To support the content acquisition, active learning tasks were embedded to encourage inquiry, discussion, collaboration, practice, and production activities among learners (Laurillard, 2012). 
In each step/topic on the FutureLearn short courses content is acquired through reading, watching, and/or listening. This is then followed by one or more active learning task, undertaken individually with peers and/or tutors using the comment section or other formats - including discussion questions, debate, comparative analysis, reflection, peerreview, collaborative writing/annotation, quiz, Padlet activities, etc. (Figure 2, based on the work of Laurillard (2012)).

Figure 2. Active learning activities following each FutureLearn content acquisition step/topic.

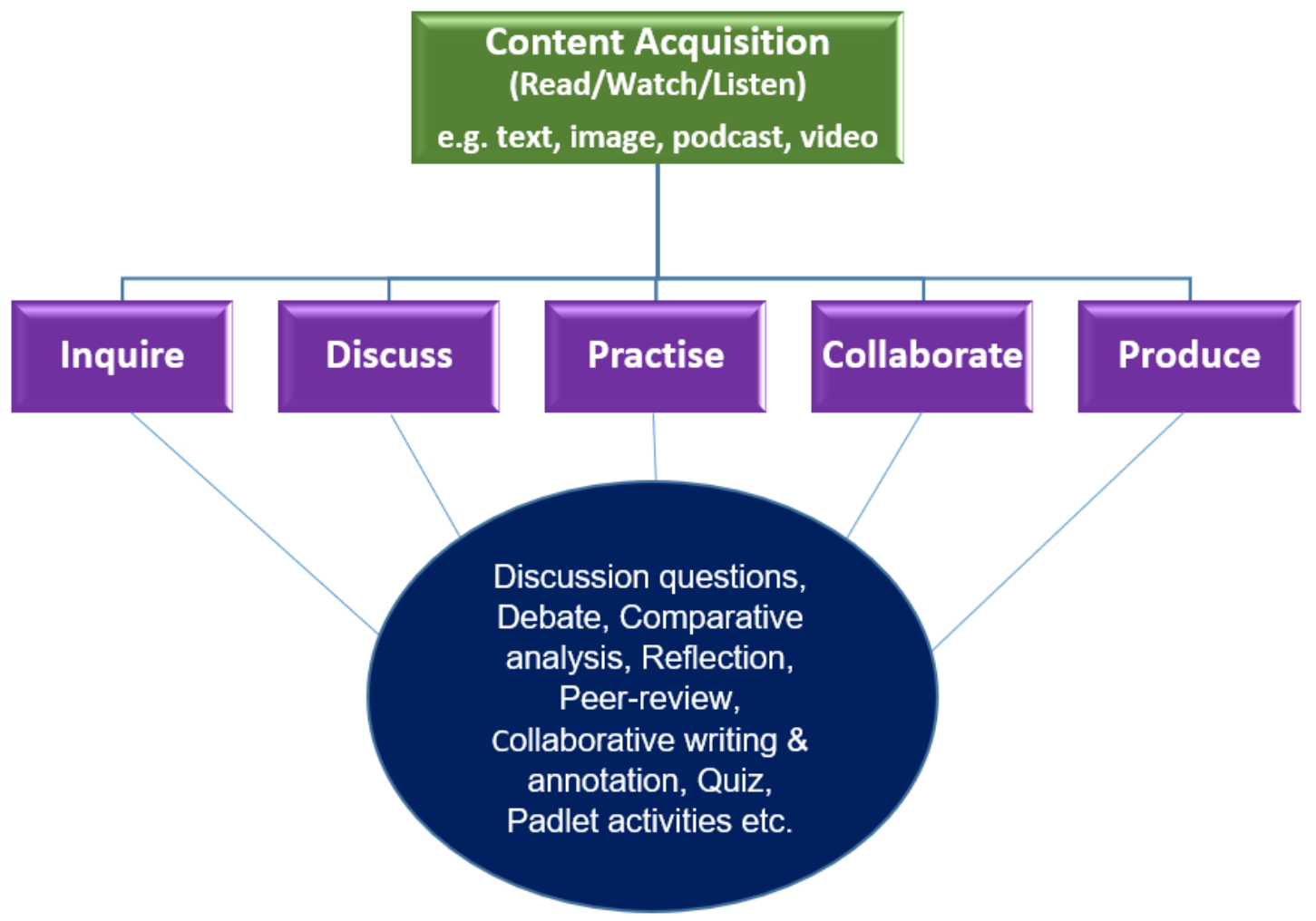

Through the two-prong approach, this redesign provides an integration of lectures (content acquisition materials) with seminar/workshop activities (active learning tasks) into one platform. Primarily, the asynchronous nature enables both educators and students to cope with the challenges of teaching and learning during the heat of the pandemic. Moreover, it offered students the benefits of flexible learning and open and on-going access to learning materials. 
The module evaluation feedback from students was very positive with $100 \%, 89 \%$, and $95 \%$ overall satisfaction in the first, second, and third run respectively. However, some qualitative comments raised issues on the task overload and the need for live and face-toface classes.

\section{Recommendations}

1. Application of Conversational Framework in designing asynchronous teaching and learning activities would benefit from the two-pronged approach involving a combination of content acquisition materials with complementary active learning tasks.

2. The use of a storyboard and module/course mapping process helps to see the whole picture and ensure consistency throughout the FutureLearn course content design. In addition, a collaboration (co-creation) approach would enrich the story boarding and design thinking process.

3. The tutor/designer must know their target students' needs. While many students engaged well with the use of the FutureLearn platform, others preferred live sessions as they had registered to study face-to-face. Hence, future design may be more relevant for students who opt for blended and/or online learning.

4. Due to the rapid nature of the redesign, sense check was conducted by learning designers. However, in hindsight, students' views are needed to enhance the design process.

5. While the use of FutureLearn promotes asynchronous facilitation of teaching and learning, there is a risk of additional workload for both tutors and students. Although workload estimation is difficult to predict in designing and delivery, it is important to prevent burnout or disengagement.

6. During the delivery process, tutors could supplement both content acquisition and active learning tasks on FutureLearn with external online collaborative tools, links, and updates using interactive comments and pinned post functions in relevant steps. Also, where possible, it is beneficial to provide opportunity for live interactive sessions to foster a sense of belonging among learners. 


\section{References}

Adedoyin, O. B. and Soykan, E. (2020) 'Covid-19 pandemic and online learning: the challenges and opportunities', Interactive Learning Environments, pp.1-13. https://doi.org/10.1080/10494820.2020.1813180.

Biggs, J. B. and Tang, C. (2011) Teaching for quality learning at university. Maidenhead: McGraw Hill Education and Open University Press.

Laurillard, D. (2012) Teaching as a design science: building pedagogical patterns for learning and technology. New York and London: Routledge.

Laurillard, D. (2020) 'The significance of Constructionism as a distinctive pedagogy', in Tangney, B., Rowan Byrne, J. and Girvan, C. (eds.) CONSTRUCTIONISM 2020: Proceedings of the 2020 Constructionism Conference. University of Dublin, Dublin 26-29 May. Dublin: Trinity College, University of Dublin, pp.29-37.

Owston, R., York, D. and Murtha, S. (2013) 'Student perceptions and achievement in a university blended learning strategic initiative', The Internet and Higher Education, 18, pp.38-46. http://dx.doi.org/10.1016/j.iheduc.2012.12.003.

Waha, B. and Davis, K. (2014) 'University students' perspective on blended learning', Journal of Higher Education Policy and Management, 36(2), pp.172-182. https://doi.org/10.1080/1360080X.2014.884677.

Young, C. and Perović, N. (2016) 'Rapid and creative course design: as easy as ABC?'. Procedia-Social and Behavioral Sciences, 228, pp.390-395. https://doi.org/10.1016/j.sbspro.2016.07.058.

\section{Author details}

Ikedinachi Ogamba is an Assistant Professor and Director of MSc Global Healthcare Management at Coventry University, UK. He has a broad experience of leading the design 
and delivery of learning and teaching in higher education, and leadership and management experience in global health and development practice. He is a Senior Fellow of HEA, with SoTL interests in design, innovation, e-learning, and inclusive and authentic curriculum. 